\title{
ANALISIS KEMAMPUAN KOMUNIKASI MATEMATIS SISWA SMK DI KOTA CIMAHI PADA MATERI PROGRAM LINEAR
}

\author{
Adi Rustandi ${ }^{1}$, Rendi Firmansyah ${ }^{2}$ \\ 1,2 IKIP Siliwangi, Jl. Terusan Jendral Sudirman, Cimahi Tengah, Kota Cimahi, Jawa Barat \\ adidewa090@gmail.com
}

\begin{abstract}
Mathematics is the ability of students to convey mathematical messages or ideas, which are symbols, mathematical formulas or graphs, as well as complete mathematics. The importance of mathematical communication is to help students sharpen ways to improve and improve both social problems or solve mathematical problems. The research method used is descriptive qualitative. The sample in this study were 3 students of class XI with high, medium, and low abilities in SMK PUSDIKHUBAD Cimahi. There were five communication questions that were given that were agreed with each student. Then the results obtained are the results of mathematical communication of vocational students in Cimahi City based on written tests and the results of interviews with students who are still lacking.
\end{abstract}

Keywords: Mathematical Communication, Linear Program.

\begin{abstract}
Abstrak
Kemampuan komunikasi matematis adalah kemampuan siswa untuk menyampaikan pesan atau ide matematika baik itu berupa simbol, rumus matematika ataupun grafik serta gagasan matematika dalam menyelesaikan suatu masalah. Pentingnya komunikasi matematis yaitu membantu siswa menajamkan cara berpikir serta meningkatkan keterampilan baik itu sosial ataupun menyelesaikan suatu masalah matematik. Metode penelitian yang digunakan adalah kualitatif deskriptif. Adapun sampel dalam penelitian ini adalah 3 orang siswa kelas XI dengan kemampuan tinggi, sedang, dan rendah di SMK PUSDIKHUBAD Cimahi. Adapun instrumen tes kemampuan komunikasi yang diberikan sebanyak 5 soal yang disertai dengan wawancara pada masing-masing siswa. Kemudian hasil yang diperoleh adalah tingkat kemampuan komunikasi matematis siswa SMK di Kota Cimahi berdasarkan pada tes tulis dan hasil wawancara dengan siswa masih tergolong kurang.
\end{abstract}

Kata kunci: Komunikasi Matematik, Program Linear.

Komunikasi matematis menurut Schoen, Bean, dan Zibart (Hulukati) merupakan kemampuan menjelaskan algoritma dan cara unik menyelesaikan pemecahan masalah (Nurhayati, 2019; Bernard \& Senjayawati, 2019), mengkontruksi dan menjelaskan sajian fenomena dunia nyata secara grafik, kata kata dan kalimat, persamaan, tabel, dan sajian secara fisik, memberikan dugaan tentang gambar gambar geometri (Hendriana, Rohaeti, dan Sumarmo, 2017: 60), sejalan dengan pengertian komunikasi menurut Priatna dalam Muharrom (2014).

Pentingnya komunikasi matematis menurut Asikin (Yonandi) dalam Hendriana dan Soemarmo (2014) dan Baroody (Yonandy) dalam Chorida (2013) yaitu membantu siswa menajamkan cara siswa berpikir, sebagai alat untuk menilai pemahaman matematika, membantu siswa mengorganisasi pengetahuan matematik mereka, membantu siswa membangun pengetahuan matematikanya, meningkatkan kemampuan pemecahan masalah matematik, memajukan penalarannya, membangun kemampuan diri, meningkatkan keterampilan sosialnya, serta bermanfaat dalam mendirikan komunikasi matematis (Maharani \& Bernard, 2018; Timutius, 2018). 
Adapun indikator komunikasi matematis menurut Sumarmo dalam (Darkasyi) dan Bernard (2015) yang telah ditulis ulang sesuai dengan bahasa penulis yaitu 1) menghubungkan benda-benda nyata, gambar dan diagram ke dalam ide matematika; 2) menyatakan peristiwa sehari-hari dalam bahasa dan symbol matematika; 3) menjelaskan ide situasi menggunakan metode lisan, tertulis, konkrit, grafik, gambar dan aljabar; 4) mendengarkan, berdiskusi, dan menulis tentang matematika; 5) membuat konjektur, merumuskan definisi, dan generalisasi.

Namun berdasarkan penelitian yang telah dilakukan oleh Senjayawati (2012) bahwa tingkat kemampuan komunikasi matematika siswa SMK di Kota Cimahi masih tergolong rendah dilihat dari rata-rata hasil Ujian Nasional mata pelajaran matematika. Sejalan dengan pernyataan Ansari dalam Simamura (2017) bahwa tingkat kemampuan komunikasi siswa SMK masih tergolong rendah.

Berkaitan dengan pentingnya kemampuan komunikasi yang sejalan dengan materi program linear dimana menyelesaikan masalah yang bersifat kontekstual ke dalam ide atau model matematika. Siswa dituntut untuk dapat mengumpulkan data serta mengkomunikasikan permasalahan yang disajikan dalam bentuk soal cerita dalam kehidupan sehari hari menjadi model matematika (Isnaeni, et. Al, 2019). Karena siswa akan merasa pembelajaran lebih bermakna ketika dikaitkan dengan kehidupan yang mereka alami (Wiliawanto, et. Al, 2019; Bernard \& senjayawati, 2019).

Berdasarkan pada pernyataan Idris dalam Simamura (2017) soal cerita yang menyebabkan siswa mengalami kesulitan dalam menyelesaikan masalah program linear. Sesuai dengan penelitian yang telah dilakukan oleh Burhanudin (Simamura, 2017) di SMK Sukoharjo kesalahan yang sering dilakukan siswa dalam menyelesaikan masalah program linear diantara dalam memahami soal, membuat model matematika serta kesalahan dalam perhitungan. Menyikapi hal tersebut maka peneliti perlu melakukan studi pendahuluan untuk mengetahui kemampuan komunikasi matematis siswa SMK di Kota Cimahi dalam materi program Linear.

\section{METODE}

Penelitian ini tergolong dalam penelitian deskriptif kualitatif yang bertujuan untuk mendeskripsikan kesalahan siswa dalam menyelesaikan soal program linear dilihat dari tingkat kemampuan komunikasi matematis siswa SMK. Data penelitian ini berupa jawaban tertulis dan lisan yang diperoleh dari tes tertulis dan wawancara. Sampel penelitian ini yaitu 3 orang siswa kelas XI di SMK PUSDIKHUBAD Cimahi dengan kemampuan tinggi, sedang dan rendah. Adapun instrumen yang diberikan pada siswa sebanyak 5 soal yang disertai dengan wawancara pada masing-masing siswa.

\section{HASIL}

Penelitian ini dilakukan pada 3 orang siswa yang diantaranya memiliki kemampuan tinggi, sedang dan rendah berdasarkan nilai KKM matematika di sekolah SMK PUSDIKHUBAD.

\section{Analisis Soal Nomor 1}

Pertanyaan : Pak Budi adalah seorang pedagang roti. Beliau menjual roti menggunakan gerobak yang hanya dapat memuat 300 . Roti yang dijualnya adalah roti manis dan roti tawar dengan harga masing 
masing adalah Rp 500, 00 dan Rp 400, 00 per bungkusnya. Apabila modal yang dimiliki oleh Pak Budi adalah Rp 140.000,00, dapatkah kamu menentukan:

a) Model Matematika

b) Gambar himpunan penyelesaiannya

Indikator kemampuan komunikasi : Menyatakan peristiwa sehari hari dalam bahasa dan simbol matematika.

Jawaban siswa I (Berkemampuan Tinggi):

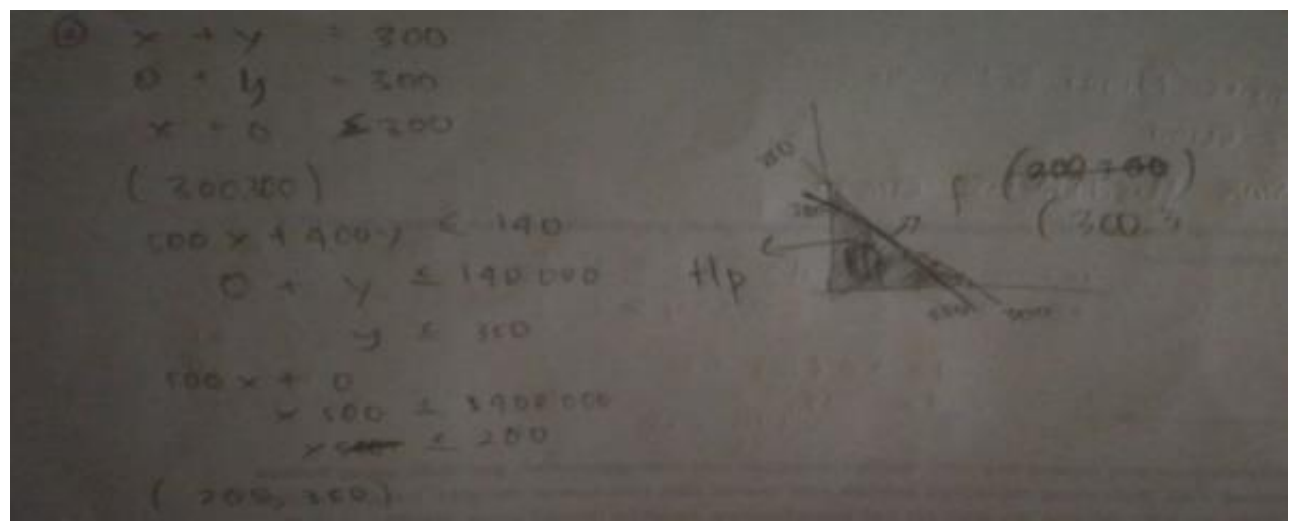

Gambar 1. Jawaban Siswa berkemampuan Tinggi

Wawancara Guru (G) dan Siswa(S):

G :"Jawaban nya sudah hampir sempurna, lain kali diberi keterangan juga jika membuat grafik pakai penggaris ya."

S :"iya bu tadi saya males nulis soalnya."

G :"Dan coba perhatikan kenapa tiba-tiba angkanya bisa jadi 140?."

S :"Oia bu saya baru sadar, karena saya liat angka lainnya ratusan jadi saya langsung nulis 140."

G :"Jadi apakah kamu mengalami kesulitan ketika diberikan soal yang berkaitan dengan kehidupan sehari-hari kemudian kamu ubah menjadi model matematikanya?"

S :"Alhamdulillah ngga bu, tadi saya ceroboh dan males nulis aja."

Jawaban siswa II (Berkemampuan Sedang) :

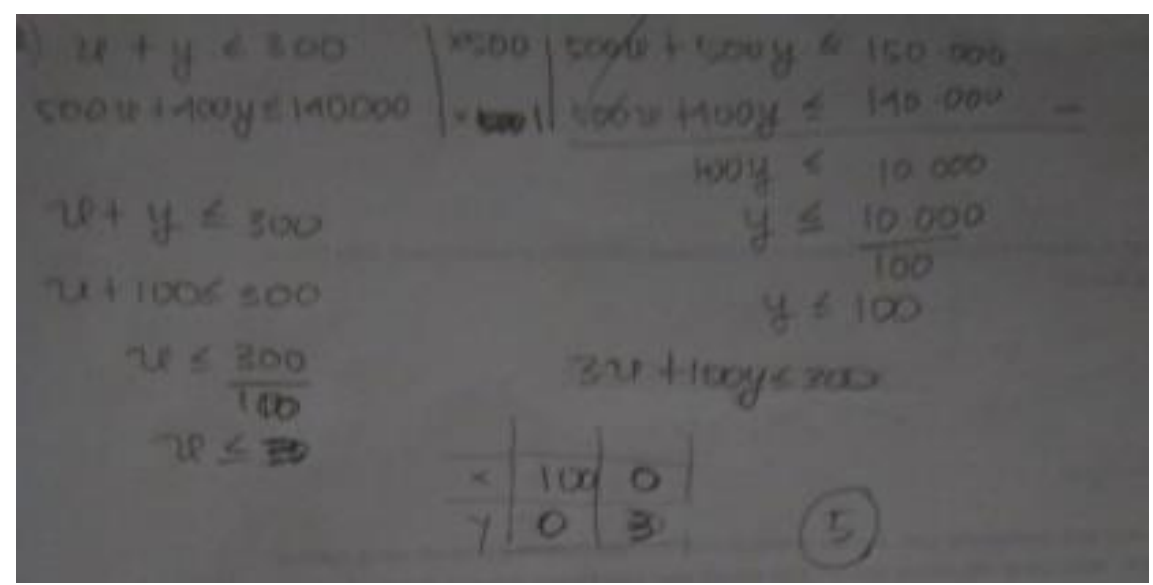

Gambar 2. Jawaban siswa berkemampuan sedang 
Wawancara :

G :“Apakah sulit mengubah peristiwa sehari-hari ke dalam symbol matematika?”

S : : :Tidak bu, cuman saya lupa cara bikin grafiknya, karena lupa jadi saya ga tau mana yang dicari titik potongnya mana yang dijadikan persamaan awalnya."

Jawaban siswa III (Berkemampuan Rendah) :

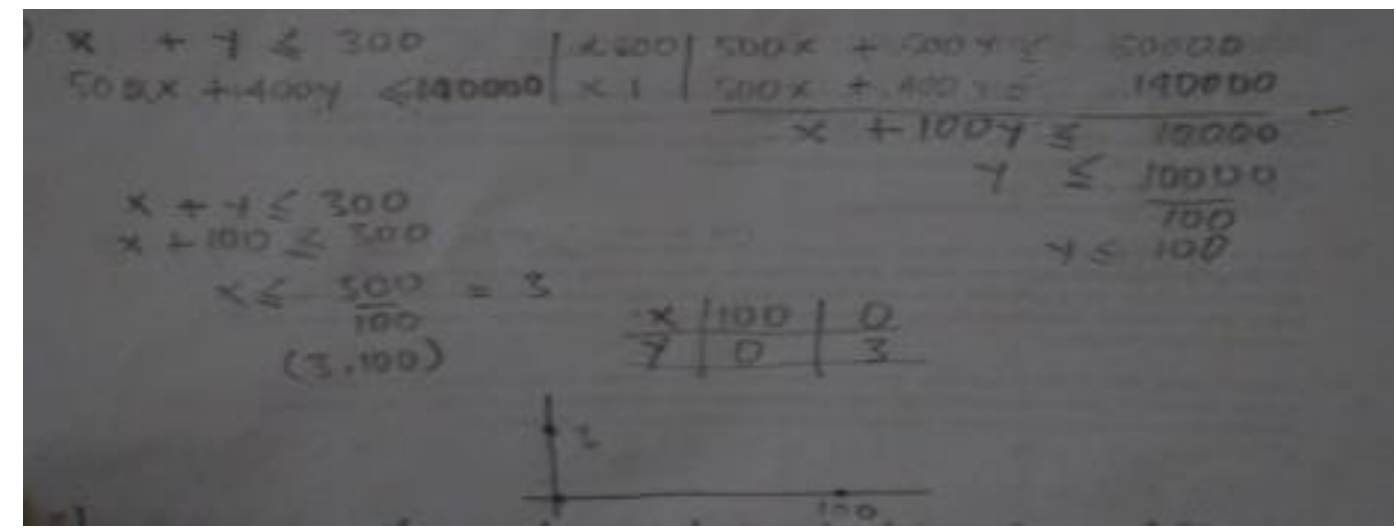

Gambar 3. Jawaban siswa berkemampuan rendah

Wawancara :

G :"Kesulitan apa yang kamu temukan ketika mengubah soal cerita dengan peristiwa sehari-hari ke dalam ide matematika?"

S : "Saya ngga tau kalo apa yang saya tuliskan itu sudah memenuhi semuanya atau belum bu."

G : :"Kemudian untuk membuat grafik dari pertidaksamaan yang diketahui apakah sulit?"

S : :Saya kurang paham bu cara membuat grafik seperti apa, pertidaksamaan yang mana yang harus saya gunakan untuk mencari titik potong."

Analisis :

Berdasarkan jawaban siswa I secara prosedural sudah betul, adapun kesalahan yang dilakukan berdasarkan wawancara yang dilakukan bukan karena siswa tidak paham namun karena kecerobohan siswa itu sendiri. Kesalahan sama yang dilakukan oleh siswa ke II dan ke III dalam menentukan titik potong dalam membuat grafik, namun berdasarkan pada wawancara yang telah dilakukan siswa II pada dasarnya ia sudah bisa meski masih tergolong kurang sama halnya untuk siswa III, namun untuk prosedur selanjutnya siswa III masih rendah. Jadi, dapat disimpulkan bahwa kemampuan menyatakan peristiwa sehari-hari dalam bahasa dan simbol matematika masih kurang.

\section{Analisis Soal Nomor 2}

Pertanyaan : Luas sebuah tempat parkir $1.760 \mathrm{~m}^{2}$. Luas rata rata untuk mobil kecil $4 \mathrm{~m}^{2}$ dan mobil besar $20 \mathrm{~m}^{2}$. Daya tampung maksimum hanya 200 kendaraan. Biaya parkir mobil kecil Rp 1.000,00/ jam dan 
mobil besar Rp 2.000,00/ jam. Jika dalam satu jam terisi penuh dan tidak ada kendaraan pergi dan datang, dapatkah kamu menentukan pendapatan maksimum yang diperoleh dari tempat parkir tersebut?. Indikator kemampuan komunikasi matematis : Menjelaskan ide situasi menggunakan metode lisan, tertulis, konkrit, grafik, gambar dan aljabar.

Jawaban siswa I (Berkemampuan Tinggi) :

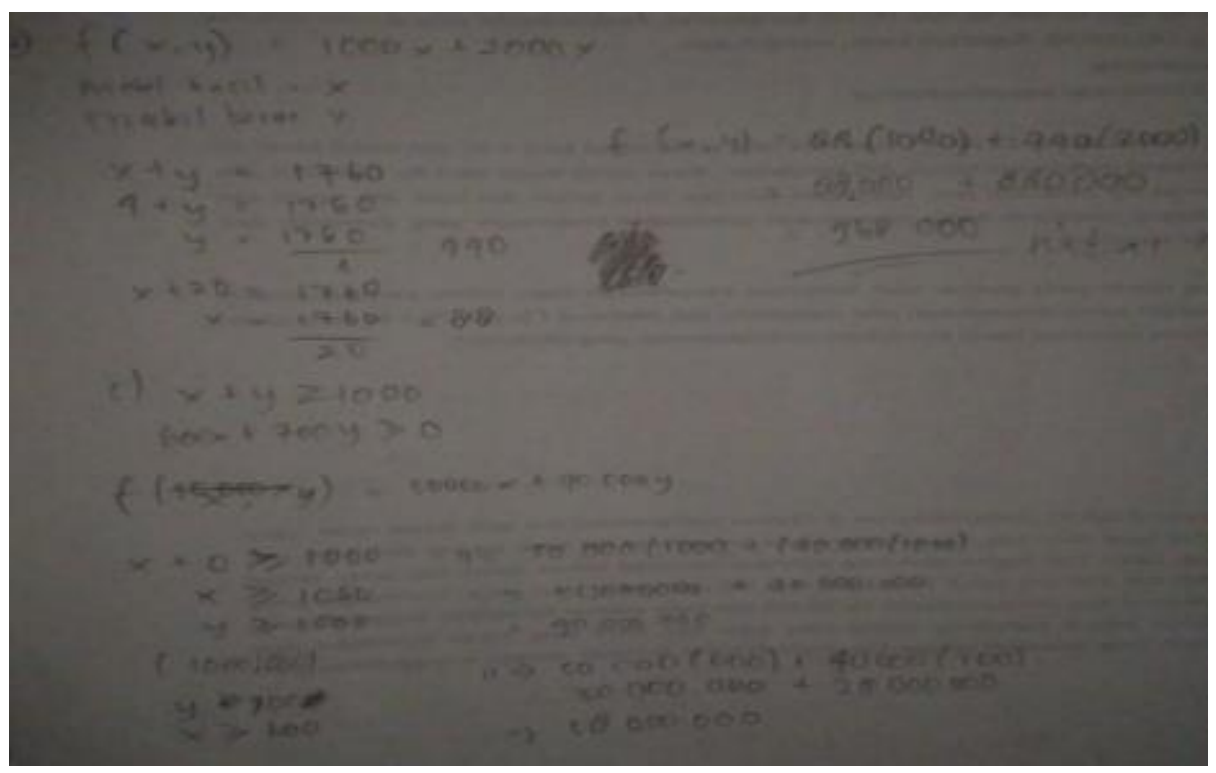

Gambar 4. Jawaban Siswa berkemampuan Tinggi

Wawancara :

G :"Kesulitan apa yang kamu hadapi ketika kamu mengerjakan soal tersebut?.”

S :"Saya ragu apakah unsur yang diketahui sudah terpenuhi semuanya atau belum."

G :"Namun ketika satu situasi dihadapkan pada kamu apakah kamu kesulitan menentukan varibel yang akan dijadikan persamaan?."

$\mathrm{S}$ :"Tidak bu, saya bisa menentukan mana yang akan dijadikan sebagai variabel yang nanti akan dijadikan persamaan, hanya saja saya kadang ragu apakah persamaan yang saya tulis sudah terpenuhi semua atau belum."

Jawaban siswa II (Berkemampuan Sedang) :

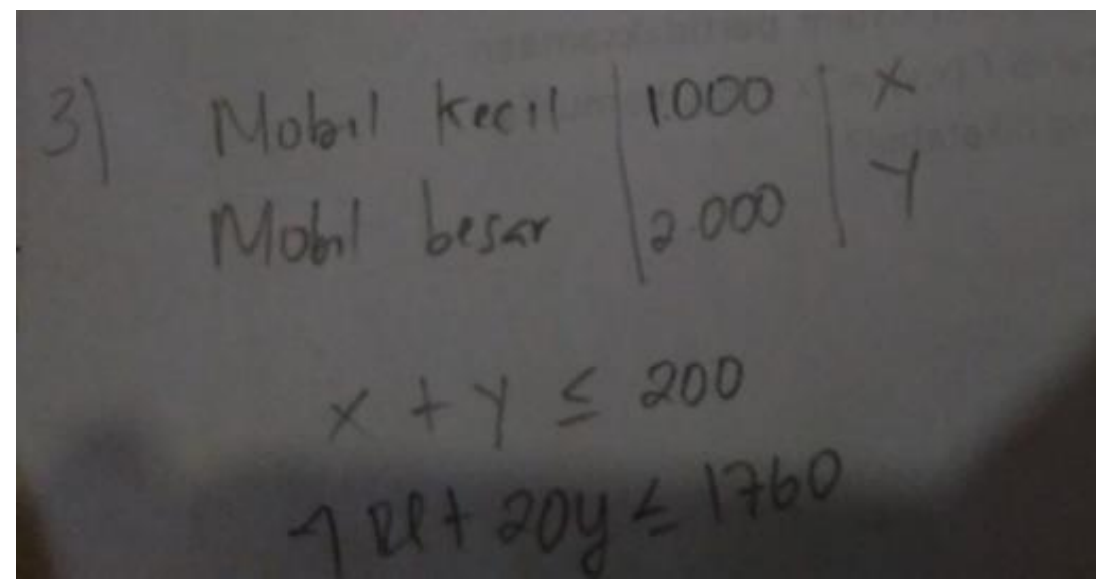

Gambar 5. Jawaban Siswa berkemampuan Sedang 
Wawancara :

G :"Kesulitan apa yang ditemukan ketika kamu akan mengubah suatu situasi menjadi model matematika?"

$\mathrm{S}$ :"Saya bingung bu memasangkan angka antara $\mathrm{x}$ dan y nya, jadi saya hanya menuliskan yang menurut saya yakin itu benar pertidaksamaannya."

G :"Lalu untuk mencari nilai maksimum itu sendiri apakah sulit?"

S :"Saya ingat bu caranya, tapi karena di awal saya bingung menentukan pasangan pertidaksamaan antara x dan y jadi saya tidak bisa melanjutkan mencari nilai maksimum."

Jawaban siswa III (Berkemampuan Rendah) :

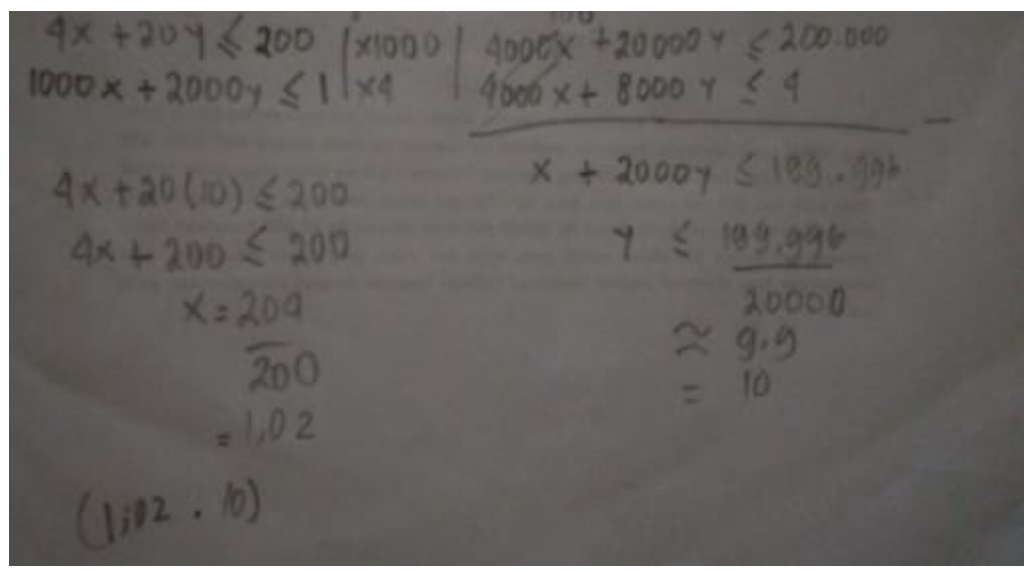

Gambar 6. Jawaban Siswa berkemampuan Rendah

Wawancara :

G :"Apakah kamu paham ketika disajikan sebuah situasi kemudian dirubah menjadi model matematika bentuk aljabar?"

$\mathrm{S}$ :"Saya hanya sebatas bisa menentukan mana $x$ dan $y$ bu sedangkan untuk membuat pertidaksamaan dengan soal yang panjang saya bingung bu."

$\mathrm{G}$ :"Apakah yang membuat kamu bingung untuk menyajikannya baik dalam bentuk tulisan atau grafik?"

S :"Saya ngga paham bu angka dari $\mathrm{x}$ harus dipasangkan dengan angka mana dari y.”

Analisis :

Berdasarkan hasil jawaban dan wawancara siswa I bahwa siswa masih kurang memahami titik mana yang akan disubstitusikan ke dalam persamaan. Sedangkan untuk siswa ke II untuk bentuk umum mengubah situasi ke dalam model aljabar matematika bisa, hanya saja ketika dihadapkan dengan serantaian keadaan siswa II kebingungan menentukan pertidaksamaan nya, sedangkan untuk siswa ke III masih kurang dalam menentukan sistem pertidaksamaan. Dengan begitu dapat disimpulkan bahwa rata-rata siswa I, II dan III dalam indikator tersebut masih tergolong rendah. 


\section{Analisis Soal Nomor 3}

Pertanyaan : Daerah yang diarsir pada gambar ialah himpunan penyelesaian suatu sistem pertidaksamaan linear. Dapatkah kamu menentukan nilai maksimum jika diketahui $f(x, y)=7 x+6 y$, kemudian dapatkah kamu membuat cerita dari system pertidaksamaan yang diketahui?

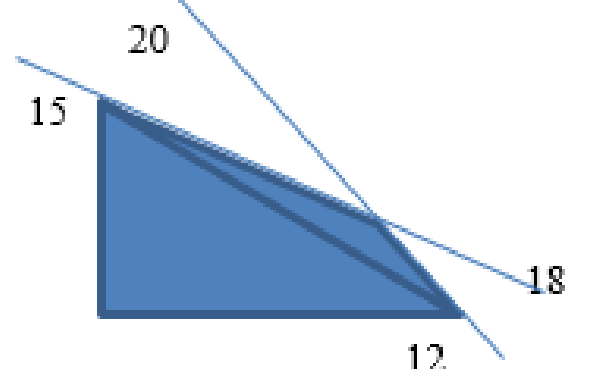

Gambar 7. Gambar soal no.3

Indikator kemampuan komunikasi matematis :

1. Menghubungkan benda-benda nyata, gambar dan diagram ke dalam ide matematika

2. Mendengarkan, berdiskusi, dan menulis tentang matematika

Jawaban siswa I (Berkemampuan Tinggi):
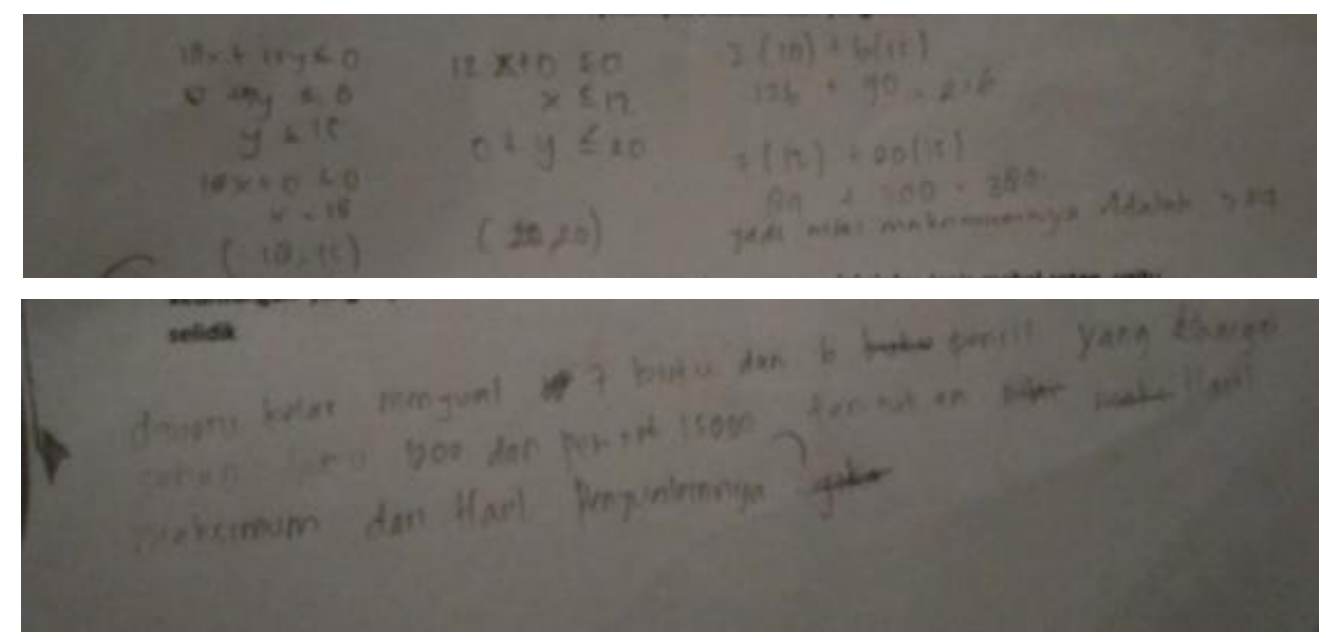

Gambar 8. Jawaban Siswa berkemampuan inggi

Wawancara :

G :"Kesulitan apa yang kamu alami ketika akan menyelesaikan soal nomor 4 Fajar?"

S :"Saya kadang bingung bu kalo dikasih diagram, dan takut salah juga."

G :"Jawabannya kurang tepat ya Fajar, dan coba perhatikan jika dilihat dari prosedur Fajar sendiri kenapa titik nya sama seperti nomor 1?."

S :"Oia bu karena saya udah pusing duluan jadi ga merhatiin betul apa yang saya kerjakan."

G :"Kemudian kesulitan apa yang kamu temukan ketika membuat cerita dari model matematika yang diketahui?." 
S :"Untuk sekedar mengarang cerita saya bisa bu, tapi saya bingung angka mana saja yang saya masukan ke dalam cerita daan juga menjadi bagian mana dalam cerita yang saya buat, jadi saya asal aja bu bikin nya."

Jawaban siswa II (Berkemampuan Sedang):
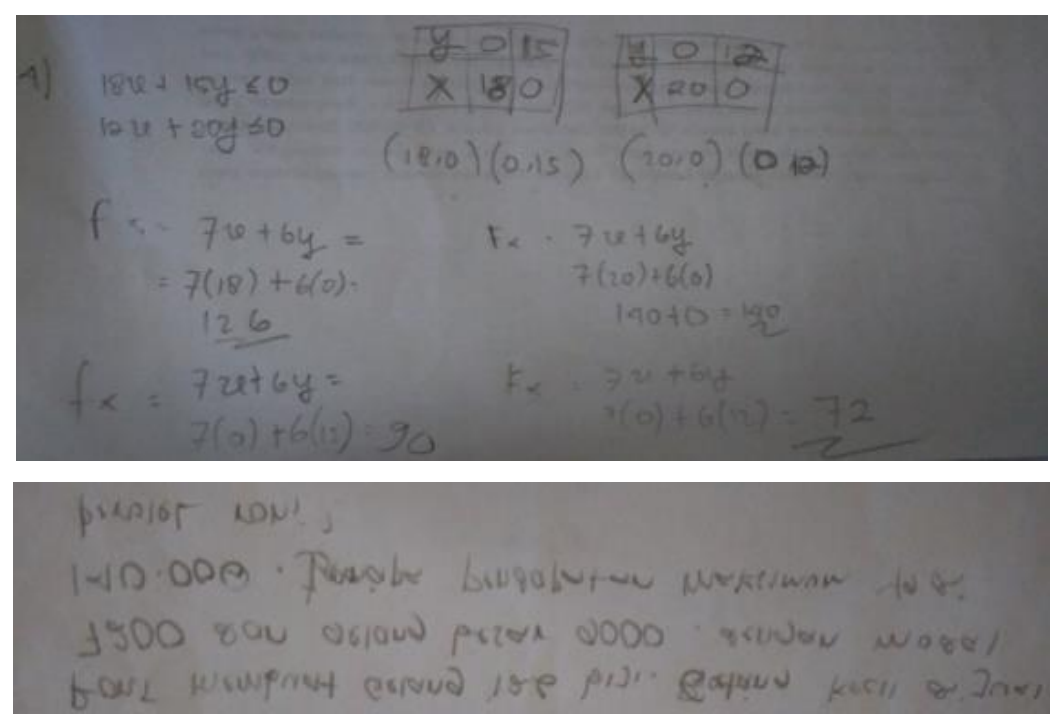

Gambar 9. Jawaban Siswa berkemampuan Sedang

Wawancara :

G :"Coba perhatikan persamaan nya bukan kah hampir mirip dengan soal nomor 1 ya?"

$\mathrm{S}$ :"Iya bu saya lupa menentukan titik potong nya, nomor 1 juga kan salah ya, tapi untuk menentukan nilai maksimum saya bisa bu karena sudah ada persamaan yang saya jadikan acuan untuk mencari nilai maksimumnya."

G :"Lalu kesulitan apa yang ditemukan untuk mengubah ide matematika menjadi cerita atau tulisan matematika?"

S :"Untuk sekedar mengarang saya bisa bu, tapi untuk menempatkan koefisien dari variabel dalam suatu cerita saya bingung."

G :"Kemudian, lain kali dibuat kesimpulannya ya."

Jawaban siswa III (Berkemampuan Rendah) :

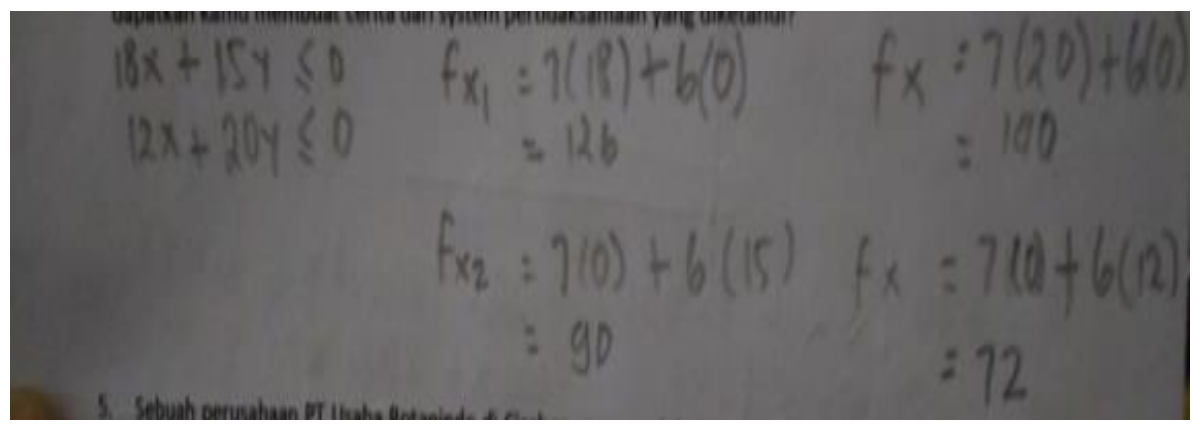

Gambar 10. Jawaban Siswa berkemampuan Rendah 
Wawancara :

G :"Kesulitan apa yang kamu hadapi ketika mengerjakan soal tersebut?"

S :"Hampir sama bu dengan soal nomor 1, saya masih bingung menentukan titik yang dilalui oleh garis lurus tersebut, jadi saya tulis saja apa yang saya lihat tanpa saya cerna."

G :"Tapi untuk mencari nilai maksimum itu sendiri apakah kamu kesulitan?.”

S :"Ngga bu soalnya sudah ada persamaan nya jadi saya tinggal substitusikan titik potong yang saya temukan."

G :"Lalu kenapa kamu tidak membuat sama sekali cerita dari ide matematika yang telah kamu tulis?."

S :"Saya bingung bu harus membuat cerita seperti apa juga di awal kan saya udah bingung cara menentukan titik jadi saya ga bikin cerita matematika nya."

G :"Kemudian lain kali beri kesimpulan atau keterangan jadi manakah nilai maksimumnya ya."

\section{Analisis :}

Siswa I dan II keliru dalam menentukan titik meskipun secara prosedur siswa sudah paham ke arah mana pertanyaan tersebut. Begitupun untuk membuat cerita tentang matematika siswa tersebut masih kurang, terlihat dari tulisan siswa yang sebenarnya hanya membuat cerita dari soal yang diketahui tidak secara menyeluruh dengan sistem pertidaksamaan yang seharusnya telah ia temukan dalam grafik, begitupun untuk siswa II yang masih bingung menempatkan variabel menjadi sebuah cerita.

Namun untuk siswa ke III masih ada miskonsepsi mengenai mentukan titik yang dilalui oleh sebuah garis, begitupun untuk menentukan nilai maksimal masih tergolong rendah karena ia bisa menstubtitusi kan nilai yang ada ke dalam persamaan yang memang sudah tertera, begitupun untuk membuat cerita matematika berdasar pada hasil wawancara siswa tersebut masih tergolong sangat rendah. Dengan begitu dapat disimpulkan bahwa rata-rata kemampuan siswa dalam mendengarkan, berdiskusi, dan menulis tentang matematika masih tergolong rendah.

\section{Analisis Soal Nomor 4}

Pertanyaan : Sebuah perusahaan PT Usaha Rotanindo di Cirebon memproduksi dua jenis mebel rotan, yaitu jenis mebel kursi dan meja. Kapasitas produksi perusahaan itu tidak kurang dari 1000 unit barang per bulan. Dari bagian marketing diperoleh informasi bahwa dalam tiap bulan terjual tidak lebih dari 600 unit untuk jenis kursi dan 700 unit untuk jenis meja. Keuntungan yang diperoleh untuk tiap unit kursi adalah Rp 50.000 dan meja sebesar Rp 40.000. Dapatkah kamu menentukan berapa banyaknya mebel jenis kursi dan meja yang harus diproduksi agar keuntungan yang diperoleh sebesar-besarnya? Cobalah kerjakan dengan menggunakan garis selidik!

Indikator kemampuan komunikasi matematis :

1. Menjelaskan ide situasi menggunakan metode lisan, tertulis, konkrit, garfik, gambar dan aljabar

2. Membuat konjektur, merumuskan definisi, dan generalisasi

Jawaban siswa I (Berkemampuan Tinggi) :

Jawaban kosong tidak di isi sama sekali 
Wawancara :

G :"Coba perhatikan soal ini hampir sama dengan soal nomor 3, sebuah situasi yang ada dikehidupan sekitarmu, apakah sulit mengubahnya ke dalam model matematika?"

S :"Sebenernya saya bisa bu membuat pertidaksamaan dari soal tersebut meski saya $\mathrm{g}$ tau itu bener atau ngga."

G :"Lalu kenapa jawabannya kosong sama sekali?”

S :"Karena saya pusing duluan dengan perintah menggunakan garis selidik, saya lupa sama sekali mengenai garis selidik, jadi ketika saya mau menuliskan pertidaksamaan yang lain saya males bu." Jawaban siswa II (Berkemampuan Sedang) :

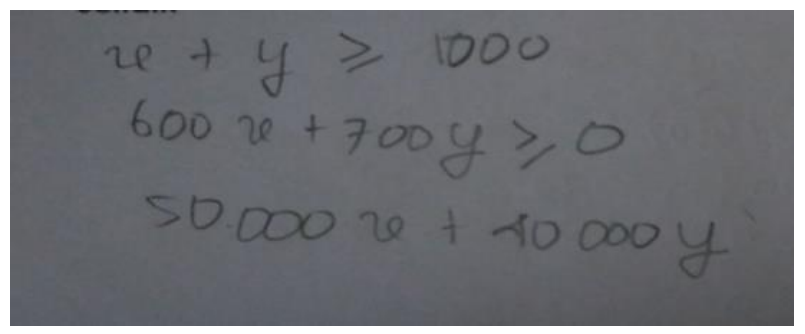

Gambar 11. Jawaban Siswa berkemampuan Sedang

Wawancara :

G :"Menurut kamu kesulitan apa yang ditemukan ketika kamu akan mengerjakan soal tersebut?."

S :"Pertama saya ragu membuat sistem pertidaksamaan nya bu karena saya bingung yang mana yang harus saya pasangkan dalam sistem pertidaksamaan tersebut yang saling berkaitan, kedua saya lupa sama sekali mengenai garis selidik bu. Jadi saya cuman isi segitu."

G :"Lalu untuk merumuskan definisi dan generalisasi kamu menemukan kesulitan juga."

S :"Saya ga terlalu memperhatikan soal bu karena pas saya baca bagian akhir saya udah ngga ngerti, jadi saya isi sebisa saya dan tidak saya cermati soal nomor 5."

Jawaban siswa III (Berkemampuan Rendah) :

Jawaban kosong.

Wawancara :

G :"Kesulitan apa yang kamu hadapi sehingga kamu tidak menuliskan jawaban sama sekali?.”

S :"Saya ngga ngerti bu dan soal nya juga kepanjangan jadi saya lewat aja."

G :"Kemudian kamu tau garis selidik itu apa?."

$\mathrm{S}$ :"Ngga tau bu, saya dulu tidak memperhatikan guru ketika guru sedang menjelaskan materi tersebut." Analisis :

Berdasarkan pada wawancara yang dilakukan terhadap siswa I pada dasar nya anak sudah bisa menghubungkan cerita dari satu situasi menjadi model matematika bentuk aljabar, namun untuk merumuskan definisi atau konjektur siswa tersebut tergolog kurang, begitu pun untuk III tertilaht dari hasil tes tertulis serta wawancara yang telah dilakukan oleh peneliti. Jadi, dapat disimpulkan secara keseluruhan bahwa kemampuan menjelaskan ide situasi menggunakan metode lisan, tertulis, konkrit, 
grafik, gambar dan aljabar juga membuat konjektur, merumuskan definisi, dan generalisasi masih tergolong rendah.

\section{KESIMPULAN}

Berdasarkan pada hasil dan pembahasan, dapat kita simpulkan beberapa kesalahan siswa dalam menjawab soal.

a. Adanya miskonsepsi antara apa yang disampaikan oleh guru dengan apa yang ditangkap oleh siswa mengenai menentukan titik potong atas garis lurus yang melaluinya.

b. Kesalahan dengan tidak dapat menentukan rumus berdasarkan pada hasil wawancara kebanyakan siswa tidak ingat dengan rumus yang telah diberikan.

c. Kesalahan dalam menafsirkan solusi karena tidak memperhatikan dengan seksama soal yang diberikan.

d. Kesalahan dalam menuliskan perhitungan atau angka karena ketidak telitian siswa.

e. Sebagian besar siswa tidak dapat membuat tulisan matematika yang sesuai dengan apa yang ditujukan.

Dengan begitu, sesuai dengan hasil analisis dari sampel siswa SMK di Kota Cimahi yang berkemampuan tinggi, sedang dan rendah menunjukan rata-rata tingkat kemampuan komunikasi matematis masih tergolong kurang. Untuk itu guru perlu memberikan banyak stimulus soal-soal yang memuat kemampuan komunikasi matematis agar kemampuan siswa dalam kognitif tersebut dapat terus meningkat.

\section{DAFTAR PUSTAKA}

Bernard, M. (2015). Meningkatkan Kemampuan Komunikasi dan Penalaran Serta Disposisi Matematik Siswa SMK dengan Pendekatan Kontekstual Melalui Game Adobe Flash CS. 4.0. Dalam Jurnal Infinity. Vol.4-No.2 Infinity 2015

Bernard, M., \& Senjayawati, E. (2019). Meningkatkan Kemampuan Koneksi Matematik Siswa SMP dengan Menggunakan Pendekatan Metaphorical Thinking Berbantuan Software Geogebra. Jurnal Mercumatika: Jurnal Penelitian Matematika dan Pendidikan Matematika, 3(2), 79-87.

Bernard, M., \& Senjayawati, E. (2019). Developing the Students' Ability in Understanding Mathematics and Self-confidence with VBA for Excel. JRAMathEdu (Journal of Research and Advances in Mathematics Education), 1(1), 45-56.

Choridah, T., D. (2013). Peran Pembelajaran Berbasis Masalah Untuk Meningkatkan Kemampuan Komunikasi Dan Berpikir Kreatif Serta Disposisi Matematis Siswa SMA. Dalam Jurnal Infinity. Vol.2-No.2 2013

Darkasyi, M., Jobar, R., Ahmad, A. (2014). Peningkatan Kemampuan Komunikasi Matematis dan Motivasi Siswa dengan Pembelajaran Quantum Learning pada Siswa SMP Negeri 5 Lhoksemawe. Dalam Jurnal Didaktik Matematika. Vol.1-No.1 ISSN 2355-4185

Hendriana, H., Rohaeti, E.,E., Sumarmo, U. (2017). Hard Skills dan Soft Skills. Bandung: Aditama 
Hendriana, H., dan Soemarmo, U. (2014). Penilaian Pembelajaran Matematika. Bandung: Aditama Isnaeni, S., Ansori, A., Akbar, P., \& Bernard, M. (2019). ANALISIS KEMAMPUAN KONEKSI MATEMATIS SISWA SMP PADA MATERI PERSAMAAN DAN PERTIDAKSAMAAN LINEAR SATU VARIABEL. Journal on Education, 1(2), 309-316.

Maharani, S., \& Bernard, M. (2018). Analisis Hubungan Resiliensi Matematik Terhadap Kemampuan Pemecahan Masalah Siswa Pada Materi Lingkaran. JPMI (Jurnal Pembelajaran Matematika Inovatif), 1(5), 819-826.

Muharom, T. (2014). Pengaruh Pembelajaran Dengan Model Kooperatif Tipe Student Teams Achievement Division Terhadap Kemampuan Penalaran dan Komunikasi Matematik Peserta Didik di SMK Manonjaya Kabupaten Tasikmalaya. Dalam Jurnal Pendidikan dan Keguruan. Vol.1-No.1 2014

Nurhayati, N., \& Bernard, M. (2019). ANALISIS KESULITAN SISWA DALAM PEMECAHAN MASALAH MATEMATIK SISWA KELAS X SMK BINA INSAN BANGSA PADA MATERI PERSAMAAN DAN PERTIDAKSAMAAN. Journal on Education, 1(2), 497-502.

Senjayawati, E. (2015). Penerapan Pendekatan Kontekstual Untuk Meningkatkan Komunikasi Matematik Siswa SMK di Kota Cimahi. Dalam Jurnal Didaktik, Vol.9-No.1 ISSN 2015.

Simamora, R. (2017). Implementasi Kurikulum 2013 Terhadap Kemampuan Komunikasi Matematis Siswa Pada Materi Program Linear di Kelas XI SMA Negeri 2 Pematangsiantar TA. 2016/ 2017. Dalam Jurnal of Mathematics Education and Science. Vol.2-No.2 2017.

Timutius, F., Apriliani, N. R., \& Bernard, M. (2018). Analisis Kesalahan Siswa Kelas IX-G di SMP Negeri 3 Cimahi dalam Menyelesaikan Soal Pemecahan Masalah Matematik pada Materi Lingkaran. JPMI (Jurnal Pembelajaran Matematika Inovatif), 1(3), 305-312.

Wiliawanto, W., Bernard, M., Akbar, P., \& Sugandi, A. I. (2019). Penerapan Strategi Pembelajaran Aktif Question Student Have Untuk Meningkatkan Kemampuan Berpikir Kritis Matematik Siswa SMK. Jurnal Cendekia: Jurnal Pendidikan Matematika, 3(1), 139-148. 